\title{
Recovery of Nickel (Ii) Ions from Electroplating Rinse Water Using Hectorite Clay
}

\author{
V.Ramamurthi (Corresponding author) \\ Department of Chemical Engineering, A.C. College of Technology \\ Anna University, Chennai- 600 025, India \\ E-mail: ramamur1951@yahoo.co.in \& pgpriya78@yahoo.co.in \\ P. Gomathi Priya \\ Department of Chemical Engineering, A.C. College of Technology \\ Anna University, Chennai- 600 025, India \\ S.Saranya \\ Department of Chemical Engineering, A.C. College of Technology \\ Anna University, Chennai- 600 025, India \\ C.Ahmed Basha \\ Pollution Control Division, Central Electro Chemical Research Institute \\ Karaikudi-630 006, India
}

\begin{abstract}
This paper describes the recovery of $\mathrm{Ni}$ (II) from electroplating rinse water using the Hectorite clay. Batch mode adsorption experiments were carried out and the effect of contact time, adsorbent dosage, $\mathrm{pH}$, initial metal ion concentration and temperature were studied. Different isotherms were obtained using nickel electroplating rinse waters of various concentrations. The ion exchange process follows second order kinetics and langmuir isotherm. The paper discusses thermodynamic parameters, including changes in Gibbs free energy, entropy and enthalpy for the ion-exchange of $\mathrm{Ni}$ (II) from electroplating rinse water on Hectorite clay, revealed that the ion-exchange process was spontaneous and exothermic under different temperatures. The maximum adsorption capacity obtained was $62.24 \mathrm{mg} / \mathrm{g}$ at $\mathrm{pH} 7-8$, the optimum adsorbent dosage and contact time was found to be $2 \mathrm{~g} / \mathrm{l}$ within 5hours.
\end{abstract}

Keywords: Nickel, Hectorite, Rinse water, Adsorption and kinetics

\section{Introduction}

Heavy metal pollution occurs in many industrial wastewater such as those produced by metal-plating, finishing facilities, dyeing operations, mining and metallurgical engineering, electroplating, nuclear power plants, aerospace industries, battery manufacturing processes, the production of paints and pigments and glass production etc. The presence of heavy metals in the aquatic ecosystem has been of increasing concern because of their toxic properties and other adverse effects on natural waters quality, such as $\mathrm{Ni}, \mathrm{Cu}, \mathrm{Zn}, \mathrm{Cr}, \mathrm{Cd}$ and $\mathrm{Pb}$. Elevated environmental levels of nickel ions derived from variety of sources. Nickel find its way to water bodies through waste water from metal plating industries, cadmium - nickel batteries and alloys. Exposure to nickel causes decrease in body weight, heart and liver damage and skin irritation. The higher concentration of $\mathrm{Ni}$ (II) in ingested water may cause severe damage to lungs, kidneys, gastrointestinal distress, e.g., nausea, vomiting, diarrhea, pulmonary fibrosis, renal edema, and skin dermatitis. It is also a known carcinogen (Axtell et al 2003). Various treatment technologies have been developed for the purification of water and waste water contaminated by heavy metals. The most commonly used methods for the removal of metal ions 
from industrial effluents include: chemical precipitation, solvent extraction, reverse osmosis, ultra filtration, ion exchange and adsorption. Among those methods, adsorption has been an effective separation process for a wide variety of applications. Since activated carbon is expensive, an alternate inexpensive adsorbent able to drastically reduce the cost of adsorption system has always been searched. Naturally occurring clay minerals have been very effectively used as adsorbents for the removal of various pollutants from waste water and aqueous solutions. Clays are hydrous alumino silicates broadly defined as those minerals that make up the colloid fraction of soils, sediments, rocks and water. Clay structure is layered with interlayer space and the layers may be electrically neutral or charged. The high specific area, chemical and mechanical stability, variety of structural and surface properties, higher values of cation exchange capacities, etc make clays an excellent group of adsorbents. Presence of both Bronsted and Lewis acidity on clay surface further enhance their adsorption capacity. Clay minerals in soil play the role of a natural scavenger of pollutants from water through both ion exchange and adsorption mechanism. (Baskaralingam et al 2006)

Considering favourable characteristics, adsorption of metal ions and other substances on clays has received considerable attention. For example, illite has been shown to absorb Cd (II) and natural bentonite eliminates zinc from aqueous solution. Removal of $\mathrm{Cr}$ (III), Ni (II), $\mathrm{Cu}$ (II) and Cd (II) by natural and Na-exchanged bentonites is also reported. (Naseem et al 2001) reported that $\mathrm{Pb}$ (II) can be removed from aqueous/acidic solutions by using bentonite as an adsorbent. (Bektas et al 2004) reported the adsorption of lead ions from aqueous solutions by natural sepiolite. (Krishna et al 2006) reported the removal of $\mathrm{Cu}$ (II) from aqueous solution by using kaolinite, montmorillonite and their modified adsorbents.

Hectorite is a crystalline sheet structure composed of two layers of silica tetrahedrons and one central dioctahedral layer, which comes under smectite group. It is 2:1 smectite clay, is composed of units made of two silica tetrahedral sheets with a central $\mathrm{Mg}$ octahedral sheet. It has permanent negative charges that arise due to the isomorphous substitution of $\mathrm{Li}^{+}$for $\mathrm{Mg}^{2+}$. The negative charge is counterbalanced by the presence of inorganic cations on the clay surface (Grim, 1968). The structure of hectorite clay was shown in Figure 1. In this present investigation the batch mode adsorption studies were carried out using hectoite clay

\section{Materials and Methods}

Nickel chloride hexahydrate, hydrochloric acid, dimethyl glyoxime and ammonia solution are obtained from Ranbaxy fine chemicals Ltd, New Delhi, India. Hectorite was obtained from Clay Mineral Society, CA, USA. Chemical Formula: $\mathrm{Na} 0,3(\mathrm{Mg}, \mathrm{Li}) 3 \mathrm{Si}_{4} \mathrm{O}_{10}(\mathrm{OH})_{2}$ also the properties of hectorite clay was shown in table 1 . The amount of nickel present in the solution is determined by using absorbance value noted from UV - Visible Spectrophotometer (HITACHI U 2000 Spectrophotometer).

\subsection{Generation of nickel electroplating wastewater}

The electrolytic cell is comprised of a set of electrodes viz. copper sheet cathode and nickel anode, placed in the acidic nickel laden solution. An electric current is applied across the electrodes and through the solution. In the acidic nickel bath solution ( $\mathrm{pH}$ value is 4.8) the copper sheets of surface area $7.5 \times 5.0 \mathrm{~cm}^{2}$ (of $2 \mathrm{~mm}$ thick) is the work piece and nickel metal sheet of surface area as $6.5 \times 5 \mathrm{~cm}^{2}$ (of $5 \mathrm{~mm}$ thick) were used as cathode and anode respectively. The experiment was carried out at a fixed current density $\left(0.024 \mathrm{~A} / \mathrm{cm}^{2}\right)$. The cathode was pre-treated and pickling was done for three minutes to remove dust and rust on the surface. When current is passed through an electrolyte the positively charged metal ions are drawn to the negatively charged cathode where they deposit onto the surface. The electroplating was done in the acidic bath for 10 minutes. One liter distilled water containing tanks were kept to rinse the cathode after electroplating. The rinsing was done for 10 seconds in each tank. The rinse water collected in the first tank (spray rinse and drag out) was not taken for adsorption studies, as it will be used as to make solution for evaporation loss during plating. And the other rinse waters collected were containing heavy metal concentrations from $24.9 \mathrm{mg} \mathrm{L}^{-1}, 43.4 \mathrm{mg} \mathrm{L}^{-1}$, and $60.8 \mathrm{mg} \mathrm{L}^{-1}$ were used for further experiments.

\section{Adsorption Studies}

Batch adsorption studies were carried out using hectorite clay. All the adsorption experiments were carried out with 50 $\mathrm{ml}$ of rinse water solution of required concentrations $\left(24.9,43.4\right.$ and $\left.60.8 \mathrm{mg} \mathrm{L}^{-1}\right)$ at solution $\mathrm{pH}$ in a thermo stated orbital shaker (NEOLAB, Mumbai) at a fixed shaking speed of $150 \mathrm{rpm}$. The experiments were carried out for various adsorbent dosages, different initial Ni (II) ions concentration, for various contact time, $\mathrm{pH}$ and temperature. $\mathrm{pH}$ was measured using a pH meter (Elico model LI 120, Hyderabad, India). For the studies on the effect of $\mathrm{pH}$, it was varied from 2 to 12 in metal ion rinse solution concentration of $43.4 \mathrm{ppm}$ and $60.8 \mathrm{ppm}$. The solution was adjusted to the desired value using $0.1 \mathrm{~N}$ hydrochloric acid solution and $0.1 \mathrm{~N}$ sodium hydroxide solution. Temperature studies were carried out for the range of $30^{\circ} \mathrm{C}$ to $40^{\circ} \mathrm{C}$. From the initial and final concentration, percentage removal can be calculated by

$$
\text { \% Re moval }=\frac{\left(C_{0}-C_{f}\right)}{C_{0}} \mathrm{X} 100
$$


Where, $\mathrm{C}_{\mathrm{o}}$ - initial concentration of nickel in $\mathrm{mg} \mathrm{L}^{-1}$,

$$
\mathrm{C}_{\mathrm{f}} \text { - final concentration of nickel in } \mathrm{mg} \mathrm{L}^{-1}
$$

The data obtained in batch model kinetics were used to calculate the equilibrium metal uptake capacity. It was also calculated for adsorptive quantity of nickel by using the following expression:

$$
q_{e}=\frac{V\left(C_{0}-C_{e}\right)}{w}
$$

Where $\mathrm{q}_{\mathrm{e}}$ is the equilibrium metal ion uptake capacity in $\mathrm{mg} \mathrm{g}^{-1} \mathrm{~V}$ the sample volume in litre, $\mathrm{C}_{\mathrm{o}}$ the initial metal ion concentration in $\mathrm{mg} \mathrm{l}^{-1}, \mathrm{C}_{\mathrm{e}}$ the equilibrium metal ion concentration in $\mathrm{mg}^{-1}$ and $\mathrm{w}$ is the dry weight of adsorbent in grams.

\section{Kinetics of Adsorption}

The order of adsorbate - adsorbent interactions has been described by using various kinetic models. Traditionally, the well-known pseudo first-order model of Lagergren has found general use, but second-order kinetics has also been applied with success by various authors to describe the interactions (Krishna et al 2004).

When adsorption is preceded by diffusion through a boundary, the kinetics in most cases follow the pseudo first-order rate equation of Lagergren.

$$
\frac{d q_{t}}{d t}=K_{1}\left(q_{e}-q_{t}\right)
$$

where $\mathrm{q}_{\mathrm{t}}$ and $\mathrm{q}_{\mathrm{e}}$ are the amount adsorbed at time $\mathrm{t}$ and at equilibrium, and $\mathrm{K}_{1}$ is the rate constant of the pseudo first-order adsorption process. The integrated rate law, after applying the initial condition of $\mathrm{q}_{\mathrm{t}}=0$ at $\mathrm{t}=0$, is

$$
\log \left(q_{e}-q_{t}\right)=\log q_{e}-K_{2} \frac{t}{2.303}
$$

The plot of $\log \left(q_{e}-q_{t}\right)$ vs. $t$ gives a straight line for first-order kinetics, which allows computation of the adsorption rate constant, $\mathrm{k}_{1}$. If the experimental results do not follows Eqs. (3) And (4), they differ in two important aspects: (i) $\mathrm{k}_{1}$ $\left(\mathrm{q}_{\mathrm{e}}-\mathrm{q}_{\mathrm{t}}\right)$ does not represent the number of available sites, and (ii) $\log \left(\mathrm{q}_{\mathrm{e}}\right)$ is not equal to the intercept of the plot of log $\left(\mathrm{q}_{\mathrm{e}}-\mathrm{q}_{\mathrm{t}}\right)$ against $\mathrm{t}$. in such cases, the pseudo second-order kinetics (Ho et al 2002) given by

$$
\frac{d q_{t}}{d t}=K_{2}\left(q_{e}-q_{t}\right)
$$

Where $\mathrm{K}_{2}$ is the second-order rate constant, and for the boundary conditions $\mathrm{t}=0$ to $\mathrm{t}=\mathrm{t}$ and $\mathrm{q}_{\mathrm{t}}=0$ to $\mathrm{q}_{\mathrm{t}}=\mathrm{q}_{\mathrm{t}}$, the integrated form of the equation is

$$
\frac{t}{\mathrm{q}_{\mathrm{t}}}=\frac{1}{K_{2} q_{e}{ }^{2}}+\frac{1}{\mathrm{q}_{\mathrm{e}}} \mathrm{t}
$$

The rate constant for intra-particle diffusion $\left(\mathrm{k}_{\mathrm{id}}\right)$ is calculated by the following equation as (Weber and morris, 1962)

$$
q_{t}=k_{i d} t^{1 / 2}
$$

Where $\mathrm{q}_{\mathrm{t}}$ is the amount of $\mathrm{Ni}$ (II) ions adsorbed $\left(\mathrm{mg} \mathrm{g}^{-1}\right)$ at time $\mathrm{t}(\mathrm{min})$ and $\mathrm{k}_{\text {id }}\left(\mathrm{mg} \mathrm{g}^{-1} \mathrm{~min}^{-1 / 2}\right)$ is the rate constant for intra-particle diffusion. Values of $k_{i d}$ were calculated from the slopes of the linear plots of $\mathrm{q}_{\mathrm{t}}$ versus $\mathrm{t}^{1 / 2}$.

\section{Isothermal Adsorption Studies}

\subsection{Langmuir isotherm}

The Langmuir adsorption isotherm (Langmuir, 1916) was probably the most widely applied adsorption isotherm. A basic assumption of the Langmuir theory is that adsorption takes place at specific homogeneous sites within the adsorbent. The saturated monolayer isotherm can be represented as

$$
q_{e}=\frac{q_{\max } k C_{e}}{1+k C_{e}}
$$

Where $c_{\mathrm{e}}$ is the equilibrium concentration $\left(\mathrm{mg} \mathrm{L}^{-1}\right), q_{\mathrm{e}}$ the amount of metal ion adsorbed ( $\left.\mathrm{mg} \mathrm{g}^{-1}\right), q_{\max }$ for a complete monolayer $\left(\mathrm{mg} \mathrm{g}^{-1}\right)$, where the constant related to adsorption capacity and $\mathrm{b}$ is the constant related to the affinity of the binding sites and energy of adsorption $\left(\mathrm{L} \mathrm{mg}^{-1}\right)$.

\subsection{Freundlich isotherm}

This fairly satisfactory empirical isotherm can be used for non-ideal adsorption and is expressed by the following equation,

$$
q_{\mathrm{e}}=K_{f} \mathrm{Ce}^{1 / n}
$$


where $K_{\mathrm{F}}$ and $n$ are the Freundlich constants related to the adsorption capacity and adsorption intensity of the adsorbent respectively. The Freundlich model (Freundlich, 1906) is more widely used but provides no information on the monolayer adsorption capacity, in contrast to the Langmuir model.

\subsection{Redlich-Peterson Model}

$$
q_{e}=\frac{K_{R P} C_{e}}{\left(1+a_{R P} C_{e}^{\beta}\right)}
$$

Another three parameter Equation (10) known as Redlich - Peterson model (Redlich, Peterson, 1959) where $\mathrm{K}_{\mathrm{RP}}, \mathrm{a}_{\mathrm{RP}}$ and $\beta$ are the Redlich Peterson parameters. The exponent $\beta$ lies between 0 and 1 . When $\mathrm{a}_{\mathrm{RP}} \rightarrow 0$ isotherm is linear and if $\beta \rightarrow 1$ the isotherm obeys Langmuir. Further when $a_{R P} C_{e}^{\beta}>>1$, the model reduces to Freundlich isotherm, The Langmuir-Freundlich model.

\subsection{Sips model}

This is essentially a Freundlich isotherm which approaches an adsorption maximum at high concentrations of adsorbate. An equation mathematically equivalent to the Sips Model (Nitta et al 1984) this equation can also be obtained by assuming that the surface is homogeneous, but that the adsorption is a cooperative process due to adsorbate-adsorbent interactions. The following relation represents this model:

$$
\mathrm{q}_{\mathrm{e}}=\frac{\mathrm{K}_{\mathrm{s}} \mathrm{C}_{\mathrm{e}}^{\beta s}}{1+\mathrm{a}_{\mathrm{s}} \mathrm{C}_{\mathrm{e}}^{\beta s}}
$$

where $\mathrm{K}_{\mathrm{s}}$ the sips model isotherm constant, $\mathrm{a}_{\mathrm{s}}$ the sips model constant and $\beta_{\mathrm{s}}$ the sips model exponent. When $\mathrm{a}_{\mathrm{s}} \rightarrow 0$ isotherm is Freundlich and if $\beta \rightarrow 1$ the isotherm obeys Langmuir model. All the model parameters were evaluated using MATLAB software.

\section{Thermodynamic studies}

In environmental engineering practice, both energy and entropy factors must be considered in order to determine the spontaneous of the processes. The adsorption process of metal ions can be summarized by the following reversible process, which represents a heterogeneous equilibrium (Tahir et al 2003). The apparent distribution coefficient $\left(K_{d}\right)$ of the adsorption is defined as

$$
K_{d}=\frac{q_{e}}{C_{e}}
$$

Where $\mathrm{C}_{\mathrm{e}}$ the concentration of metal ion on the adsorbent at equilibrium $\left(\mathrm{mg} \mathrm{l}^{-1}\right)$ and $\mathrm{q}_{\mathrm{e}}$ is the equilibrium adsorption capacity $\left(\mathrm{mg} \mathrm{g}^{-1}\right)$. The $K_{d}$ value is used in the following equation to determine the Gibbs free energy of adsorption $\left(\Delta G^{0}\right)$

$$
\Delta G^{\circ}=-R T \ln K_{d}
$$

Van't Hoff equation is given by

$$
\begin{aligned}
\Delta G^{0} & =\Delta H^{0}-T \Delta S^{0} \\
\ln K_{d} & =-\frac{\Delta H^{0}}{R T}-\frac{\Delta S^{0}}{R}
\end{aligned}
$$

where $\Delta G^{0}$ is standard free energy change $(\mathrm{J}), R$ the universal gas constant $\left(8.314 \mathrm{~J} \mathrm{~mol}^{-1} \mathrm{~K}^{-1}\right)$ and $\mathrm{T}$ is the absolute temperature $(\mathrm{K})$.

The enthalpy $\left(\Delta H^{0}\right)$ and entropy $\left(\Delta S^{0}\right)$ can be obtained from the slope and intercept of a Van't Hoff equation of $\ln K_{d}$ vs. $1 / \mathrm{T}$

\section{Results and Discussion}

\subsection{Effect of Contact Time on Percentage Adsorption}

The dependence of adsorption of $\mathrm{Ni}$ (II) using hectorite clay on contact time for various concentrations at a room temperature and solution $\mathrm{pH}$ is shown in Figure. 2 The adsorption on hectorite clay increased with contact time and attained a maximum value at $5 \mathrm{~h}$ for both the solution. Further increase in contact time does not show a significant change in percentage removal (Grim, 1968). It is evident from the results that the contact time required to attain equilibrium is dependent on the initial concentration of heavy metals.

\subsection{Effect of Adsorbent Dosage on Percentage Adsorption}

To determine the necessary hectorite quantity required for the maximum removal of $\mathrm{Ni}$ (II) ions, the adsorbent dosage was increased from the range of $0.01 \mathrm{~g}$ to $0.5 \mathrm{~g}$, the effect of hectorite dosage on percentage removal was studied. From Figure.3, it is observed that there is a sharp increase in percentage removal with adsorbent dose for Ni (II). It is apparent that the percentage removal of heavy metals increases rapidly with increase in the dose of the adsorbents due to the 
greater availability of the exchangeable sites or surface area. (Selvaraj et al 1998). Hence the optimum adsorbent dosage was found to be $0.1 \mathrm{~g}$ per $50 \mathrm{ml}$ of nickel bearing rinse water effluents.

\subsection{Effect of Initial Ni (II) Ions Concentration on Percentage Adsorption}

From Fig 4 it can be observed that the percentage removal decreases with the increase in initial heavy metal concentration. Initial metal ion concentration is varied from $24.9 \mathrm{ppm}$ to $60.8 \mathrm{ppm}$ of effluent solution. At lower concentration, the percentage removal is very high and it is lower at higher concentration. This is due to availablity of same amount of adsorbent site for various amount of initial metal ion concentration. The maximum removal of $95 \%$ was attained at the initial concentration of $24.9 \mathrm{ppm}$ due to the other characteristics contents of the effluents may be low.

\subsection{Effect of $\mathrm{pH}$ on percentage adsorption}

$\mathrm{pH}$ is one of the most important parameter controlling uptake of heavy metals from wastewater and aqueous solutions. Figure. 5 shows the effect of $\mathrm{pH}$ on heavy metal removal efficiencies on hectorite. These studies were conducted at a constant initial metal ions concentration of $43.4 \mathrm{ppm}$, adsorbent dosage of $0.1 \mathrm{~g} / 1$ solution and agitation period of $5 \mathrm{~h}$ for all heavy metal ions at varying the $\mathrm{pH}(2$ to 12$)$ on hectorite. By increasing the $\mathrm{pH}$ above 10 , the metal ion precipitations take place. The percentage adsorption increases with $\mathrm{pH}$ to attain a maximum at $\mathrm{pH} 7$ and thereafter the percentage removal does not change significantly. These results are found in agreement with other studies performed with monmorillonite and bentonite. The mechanism that influences adsorption characteristics of hectorite can be given by dissolution, ion exchange/adsorption and precipitation. From the figure 5 , the lowest $\mathrm{Ni}^{2+}$ sorption rates were at $\mathrm{pH} 2$. This could be due to the increase in competition for adsorption sites by $\mathrm{H}^{+}$. The basic mechanism that governs the adsorption characteristics of hectorite at $\mathrm{pH}$ ranging between 6 to 9 is adsorption and ion exchange. At these $\mathrm{pH}$ levels exchangeable cations present at the exchangeable sites are exchanged with $\mathrm{Ni}^{2+}$ cation in the aqueous solutions (Viraraghavan et al 1994).

\subsection{Effect of temperature on percentage adsorption}

Fig.6 shows the experimental results obtained from a series of contact time studies for metal ions adsorption with an initial metal ion concentration of $43.4 \mathrm{ppm}$ and $60.8 \mathrm{ppm}$ at solution in which temperature was varied from 25 to $40{ }^{\circ} \mathrm{C}$. The adsorption of metal ions has been found to increase with an increase in temperature from 25 to $40{ }^{\circ} \mathrm{C}$. The increase in adsorption with temperature may be attributed to either increase in the number of active surface sites available for adsorption on the adsorbent or the desolation of the adsorbing species and the decrease in the thickness of the boundary layer surrounding the adsorbent with temperature, so that the mass transfer resistance of adsorbate in the boundary layer decreases. (Naseem et al 2005).

The values of $\Delta \mathrm{H}^{\circ}$ and $\Delta \mathrm{S}^{\circ}$ were calculated from the slope and intercept of the plot of $\log \mathrm{K}_{\mathrm{d}}$ against 1/T. From these values Gibbs free energy can be calculated. It is evident from the table that values of $\Delta \mathrm{H}^{\circ}$ are positive, i.e., endothermic, which is quite contrary to the usual observation. One possible explanation of endothermicity of the enthalpy of adsorption is the well-known fact that ions like Ni (II) are well solvated in water. In order for metal ions to be adsorbed, they have to lose part of their hydration sheath. This dehydration process requires energy. This energy of dehydration supersedes the exothermicity of ions getting attached to the surface. The Gibbs free energy change $\left(\Delta \mathrm{G}^{0}\right)$ is negative as expected for a spontaneous process. The rise in $\Delta \mathrm{G}^{\mathrm{o}}$ with rise in temperature shows that the reaction is more favourable at higher temperature.

\subsection{The Pseudo First-Order Kinetics}

It is well recognized that the characteristics of sorbent surface is a critical factor that affects the sorption rate parameters. To describe the changes in the sorption of ions studied with time, several kinetic models were tested. A plot of $\log \left(\mathrm{q}_{\mathrm{e}}-\mathrm{q}_{\mathrm{t}}\right)$ vs. time (figure 7) was drawn and the rate constant and $\mathrm{q}_{\mathrm{e}}$ were calculated from the slope and intercept of the plot. (Runping Han et al 2005) The plots of $\log \left(\mathrm{q}_{\mathrm{e}}-\mathrm{q}_{\mathrm{t}}\right)$ Vs time were nearly linear with regression coefficients of 0.92-0.98. However the value of $\mathrm{q}_{\mathrm{e}}$ calculated from equation does not match with experimental values shown in table.2. Hence the results were further tested for pseudo second-order kinetics.

\subsection{The Pseudo Second-Order Kinetics}

A plot of $\mathrm{t} / \mathrm{q}_{\mathrm{t}}$ Vs time (Figure 8) gives very good straight lines. Success with the second order kinetics suggests chemisorption as the rate - controlling step. Rate constant can be calculated from the slope and intercept of the plot and regression coefficients was found to be in the range of 0.99 . Thus kinetics for adsorption of nickel on hectorite clay from electroplating effluents fits well to pseudo second-order equation. Table. 3 shows the first, second order rate constants and the regression coefficients. It confirms that by increasing the initial metal ion concentration will decrease the second order rate constants.

\subsection{Intra particle diffusion}

Weber- Morris model was applied to the adsorption of $\mathrm{Ni}$ (II) on to hectoite as a function of rinse water concentration and the variation of qt vs. $\mathrm{t}^{1 / 2}$ was given in Figure 9 respectively. The linear portions of the curve do not pass through 
the origin indicating that the mechanism of $\mathrm{Ni}(\mathrm{II})$ on hectoite was complex and both the surface adsorption as well as intra particle diffusion contributes to the actual adsorption process. The intra particle rate constants for initial rinse water concentrations for both the resins were obtained from the slope of the linear portions of the plots of qt vs. $\mathrm{t}^{1 / 2}$ and the results were presented in table.2, which gives the values of $\mathrm{k}_{\mathrm{id}}$ and model constants for the hectoite with respect to initial concentration.

\subsection{Isothermal Studies}

Duplicate runs for batch mode adsorption experiments were made for each adsorbent to determine the adsorption capacity. Many models have been used to explain adsorption equilibriums, but the most important factor is to have applicability over the entire range of process conditions. The most widely used two parameter adsorption models were Langmuir and Freundlich isotherms where Redlich-Peterson isotherm and sips model were known as three parameter model. The isotherm relate metal uptake per unit weight of adsorbent $\mathrm{q}_{\mathrm{e}}$ to the equilibrium adsorbate concentration in the bulk fluid phase. The main reason for the extended use of these isotherm models is that they incorporate constants that are easily interpretable. The constants along with correlation coefficients obtained from these isotherm models are listed in Table 4. The Langmuir sorption model served to estimate the maximum metal uptake values, where they could not be reached in the experiments. The isotherm data were well fitted in all the isotherms. Figure [10-13] present the Langmuir, Freundlich, Redlich -Peterson isotherm and sips isotherm plots for nickel (II) ions adsorption on the hectorite clay using the electroplating effluents containing nickel solutions for different temperatures. Using the MATLAB software the graphs shows the high value of coefficient of correlation, for the adsorbent indicates the models fit well. The application of the Langmuir, Freundlich, Redlich-peterson model and sips isotherm data resulted in better $\mathrm{R}^{2}$ correlation coefficients $\left(\mathrm{R}^{2}=0.9\right)$ indicates good agreement between experimental and predicted data. Also it clears that the hectorite clay is more effective for heavy metals removal.

\section{Conclusion}

Thus the adsorption experiments were carried out using hectorite clay for nickel electroplating effluents. The effects of various parameters like contact time, adsorbent dosage, $\mathrm{pH}$, initial metal ion concentration and temperature on the adsorption of nickel from electroplating rinse effluent were studied. The maximum removal of Nickel (II) was found to be $95 \%$ for electroplating rinse water at initial concentration of $24.9 \mathrm{mg} / \mathrm{l}$. Equilibrium time was found to be $5 \mathrm{hrs}$ for adsorption from electroplating rinse effluent after which no effective removal was found. The effective adsorbent dosage was found to be $0.1 \mathrm{~g}$ per $50 \mathrm{ml}$ of solution for nickel bearing industrial effluents. Optimum $\mathrm{pH}$ was found to be in the range of $7-8$, at which maximum removal of nickel was observed. Effect of temperature was found to be significant as the rate of adsorption increases as the temperature increases. Thermodynamic parameters like $\Delta \mathrm{H}^{\circ}, \Delta \mathrm{S}^{\circ}$ and $\Delta \mathrm{G}^{\mathrm{o}}$ were calculated. $\Delta \mathrm{H}^{\circ}$ values were found to be positive and hence the adsorption process is endothermic. $\Delta \mathrm{G}^{\circ}$ values were found to be negative which confirms the spontaneous process. Kinetic studies were done and pseudo second-order equation was found to be fitted well when compared to pseudo first-order equation. Experimental values were fitted with various isotherms for different temperature range (303-313K) and all the isotherms were found using MATLAB software fit well. Maximum adsorption capacity was found to be $62.24 \mathrm{mg} / \mathrm{g}$ for adsorption from nickel electroplating effluent.

\section{References}

Axtell, N.R., Sternberg, S.P.K., \& Claussen, K. (2003). Lead and Ni (II) removal using Microspora and Lemna minor. Bioresour Technol., 89, 41- 48.

Baskaralingam,P., Pulikesi, M., Ramamurthi,V., and Sivanesan,.S. (2006). Equilibrium studies for the adsorption of acid dye onto modified hectorite. Journal of Hazardous Materials, B136 989-992.

Bektas,N., Agim,B.A., Kara,S. (2004). Kinetic and equilibrium studies in removing lead ions from aqueous solutions by natural sepiolite. Journal of Hazardous materials, 112, 115-122.

Freundlich, H. (1906). Uber die adsorption in losungen Z. Phys. Chem, 57, 385-470.

Grim.R.E. (1968).Clay Mineralogy, Frank Press, London, 86.

Ho,Y.S., McKay,G. (2002). Application of kinetic models to the sorption of Copper (II) on peat. Adsorption Science Technology 207, 97-815.

Krishna, G., Bhattacharyya., Arunima Sharma. (2004). Azadirachta indica leaf powder as an effective biosorbent for dyes: a case study with Congo red solutions. Journal of Environmental Management, 71, 217-229.

Krishna, G., Bhattacharyya., Sushmita Sen Gupta. (2006). Kaolinite-montmorillonite and their modified derivatives as adsorbents for removal of $\mathrm{Cu}$ (II) from aqeous solution. Separation and purification Technology, 50, 388-397.

Langmuir, I. (1916). The constitution and fundamental properties of solids and liquids, Journal of the American Chemical Society, 38, 2221-2295. 
Naseem, R., Tahir,.S.S. (2005). Removal of a Vanadium (IV) from aqueous solutios by adsorption process with Aluminium - Pillared Bentonite. Indian Engineering Chemical Resources, 44, 6667 - 6684.

Naseem,R., Tahir,S.S. (2001). Removal of Pb (II) from aqueous acidic solutions by using bentonite as an adsorbent. Water Resources, 16, 3982 - 3986.

Nitta, T., Shigetomi, T., Kuro-Oka, M., and Katayama, T. (1984). An adsorption isotherm of multi-site occupancy model for homogeneous surface. J. Chem. Engg,Japan 17, 39-52.

Redlich, O., Peterson, D.L. (1959). A useful adsorption isotherm. Journal of Physical Chemistry, 63, 1024.

Runping Han., Jinghua Zhang., Weihua Zou., Jie Shi., Hongmin Liu. (2005). Equilibrium biosorption isotherm for lead ion on chaff, Journal of Hazardous materials, B125, 266-271.

Selvaraj,K., Chandramohan,V., Pattabhi,.S. (1998). Removal of Cr (VI) from solution and chromium plating industry waste water using photofilm waste slugde. Indian Journal of Environmental Health 18, 641-646.

Tahir,S.S., Naseem Rauf. (2003). Thermodynamics studies of Nickel (II) adsorptions onto bentonite from aqueous solution. Journal of Chemical Thermodynamics, 35, 2003-2009.

Viraraghavan.T., Kapoor.A. (1994). Adsorption of mercury from wastewater by bentonite. Applied clay science, 9 , 31 49.

Weber, W.J., and Morris, C.J. (1962). Advances in water pollution research in proceedings of the first International Conference on Water Pollution Research, vol. 2, Pergamon Press, Oxford, 231.

Table 1. Properties of Hectorite

\begin{tabular}{|l|l|}
\hline Constituents & Percentage (\%) \\
\hline $\mathrm{SiO}_{2}$ & 62.71 \\
\hline $\mathrm{MgO}$ & 28.39 \\
\hline $\mathrm{Li}_{2} \mathrm{O}$ & 1.17 \\
\hline $\mathrm{Na}_{2} \mathrm{O}$ & 3.23 \\
\hline $\mathrm{H}_{2} \mathrm{O}$ & 4.70 \\
\hline $\mathrm{Na}$ & 2.40 \\
\hline $\mathrm{Mg}$ & 17.12 \\
\hline $\mathrm{Si}$ & 29.31 \\
\hline $\mathrm{H}$ & 0.53 \\
\hline O & 50.10 \\
\hline Li & 0.54 \\
\hline Specific surface area $\left(\mathrm{N}_{2}\right.$ area $)$ & $63.19\left(\mathrm{~m}^{2} \mathrm{~g}^{-1}\right)$ \\
\hline Molecular Weight & $383.25 \mathrm{gm}^{-1}$ \\
\hline Cation exchange capacity & $43.9 \mathrm{mEq}^{-100 \mathrm{~g}}$ \\
\hline
\end{tabular}


Table 2. Thermodynamic parameters for the removal of $\mathrm{Ni}$ (II) from electroplating rinse effluents

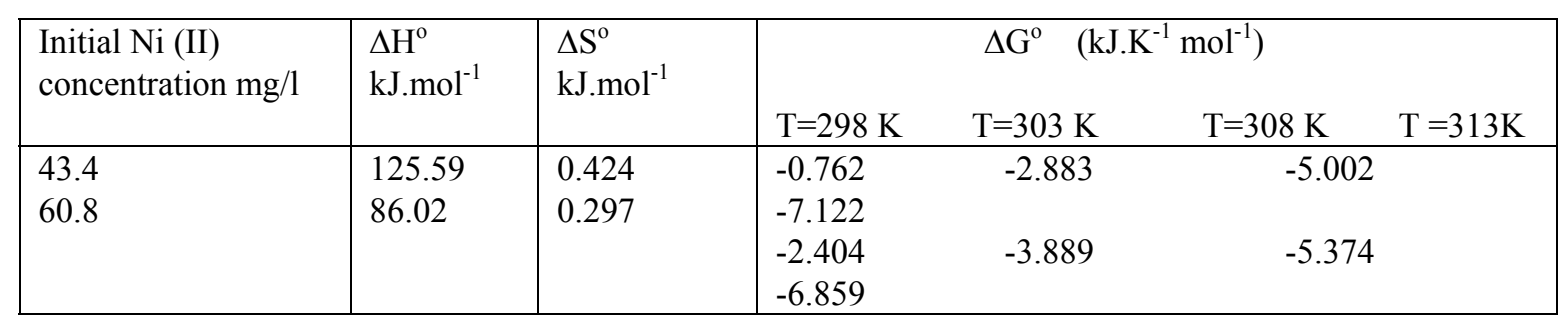

Table 3. Kinetic parameters for pseudo first-order, pseudo second order and intra particle diffusion equation for the removal of $\mathrm{Ni}$ (II) from electroplating rinse effluents

\begin{tabular}{|c|c|c|c|c|c|c|c|c|}
\hline \multirow[t]{2}{*}{$\begin{array}{l}\text { Initial concentration of } \\
\mathrm{Ni}(\mathrm{II}) \mathrm{mg} / \mathrm{l}\end{array}$} & \multicolumn{3}{|c|}{ Pseudo first-order } & \multicolumn{3}{|c|}{ Pseudo second order } & \multicolumn{2}{|c|}{$\begin{array}{l}\text { Intra particle } \\
\text { diffusion }\end{array}$} \\
\hline & $\begin{array}{l}\text { Lagergren } \\
\text { rate } \\
\text { constant, } \\
\mathrm{K}_{1} \\
\left(\min ^{-1}\right) .\end{array}$ & $\begin{array}{l}\mathrm{q}_{\mathrm{e}} \\
(\mathrm{mg} \\
\left.\mathrm{g}^{-1}\right)\end{array}$ & $\mathrm{R}^{2}$ & $\begin{array}{l}\text { Rate } \\
\text { constant } \\
\mathrm{K}_{2} \\
\left(\mathrm{~g} \mathrm{mg}^{-1}\right. \\
\left.\min ^{-1}\right)\end{array}$ & $\begin{array}{l}\mathrm{q}_{\mathrm{e}} \\
(\mathrm{mg} \\
\left.\mathrm{g}^{-1}\right)\end{array}$ & $\mathrm{R}^{2}$ & $\begin{array}{c}\text { Kid (mg } \\
\mathrm{g}^{-1} \\
\left.\min ^{1 / 2}\right)\end{array}$ & $\mathrm{R}^{2}$ \\
\hline 24.9 & 0.0066 & 2.038 & 0.9621 & 0.0137 & 11.28 & 0.9945 & 0.4413 & 0.9434 \\
\hline 43.4 & 0.004 & 2.513 & 0.9865 & 0.0038 & 18.58 & 0.9804 & 0.6735 & 0.9913 \\
\hline 60.8 & 0.0103 & 3.189 & 0.9655 & 0.0023 & 19.34 & 0.9979 & 0.7535 & 0.9154 \\
\hline
\end{tabular}

Table 4. Adsorption Isotherm Constants for the removal of $\mathrm{Ni}(\mathrm{II})$ from electroplating rinse effluents

\begin{tabular}{|c|c|c|c|c|}
\hline \multicolumn{2}{|l|}{ Temperature (K) } & $303 \mathrm{~K}$ & $308 \mathrm{~K}$ & $313 \mathrm{~K}$ \\
\hline \multirow[t]{3}{*}{ Langmuir isotherm } & $q \max \left(\mathrm{mg} \mathrm{g}^{-1}\right)$ & 18.7 & 22.64 & 62.24 \\
\hline & $\mathrm{b}\left(\mathrm{g}^{-1}\right)$ & 0.349 & 0.608 & 0.4121 \\
\hline & $\mathrm{R}^{2}$ & 0.971 & 0.978 & 0.93 \\
\hline \multirow{3}{*}{$\begin{array}{l}\text { Freundlich } \\
\text { isotherm }\end{array}$} & $\mathrm{K}_{\mathrm{f}}$ & 5.32 & 8.827 & 17.01 \\
\hline & $\mathrm{n}$ & 0.377 & 0.324 & 0.5615 \\
\hline & $\mathrm{R}^{2}$ & 0.983 & 0.976 & 0.962 \\
\hline \multirow{4}{*}{$\begin{array}{l}\text { Redlich -Peterson } \\
\text { isotherm }\end{array}$} & $\mathrm{K}_{\mathrm{RP}}$ & 5.87 & 12.43 & 8.23 \\
\hline & $a_{\mathrm{RP}}$ & 0.137 & 0.442 & -0.5 \\
\hline & $\beta$ & 0.5 & 0.688 & 0.255 \\
\hline & $\mathrm{R}^{2}$ & 0.985 & 0.985 & 0.926 \\
\hline \multirow[t]{4}{*}{ Sips isotherm } & $\mathrm{Ks}$ & 5.87 & 12.43 & 8.23 \\
\hline & $\mathrm{a}$ & 0.137 & 0.442 & -0.5 \\
\hline & $\mathrm{b}$ & 0.5 & 0.688 & 0.255 \\
\hline & $\mathrm{R}^{2}$ & 0.985 & 0.985 & 0.926 \\
\hline
\end{tabular}




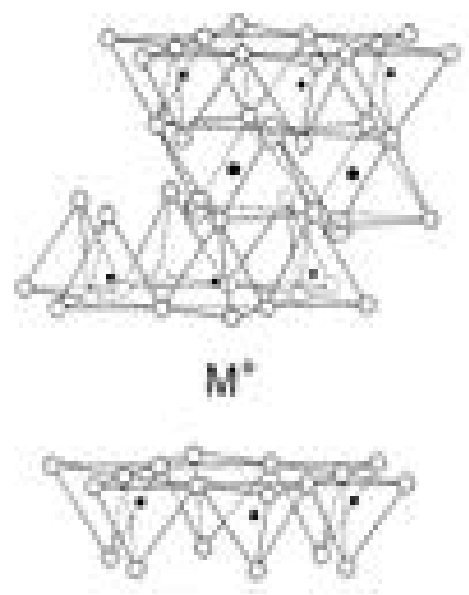

क. Oxygen

- Mg or Li

- Si

$\mathrm{M}^{+}$Interlayer cation $\left(\mathrm{Na}^{+}\right)$. exchangeable to organic ammonium ions

Figure 1. STRUCTURE OF HECTORITE

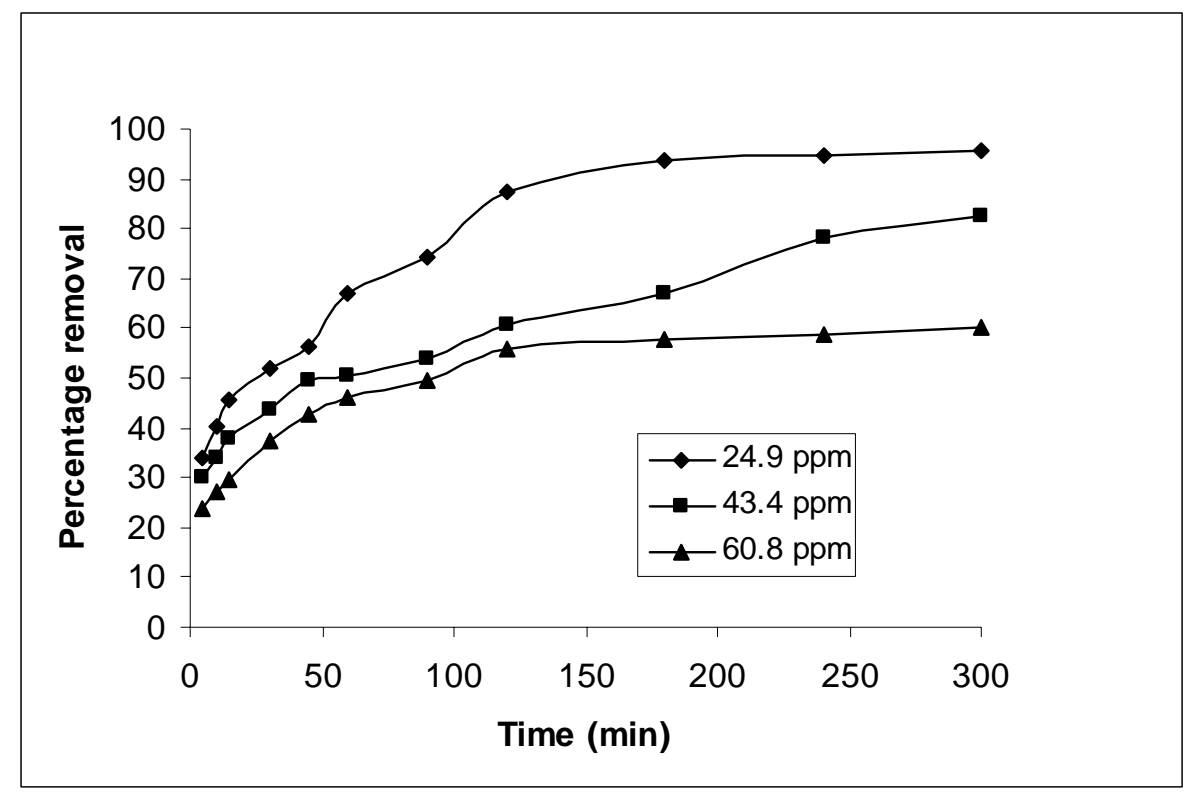

Figure 2. Effect of contact time on percentage removal of $\mathrm{Ni}$ (II) from electroplating effluent 


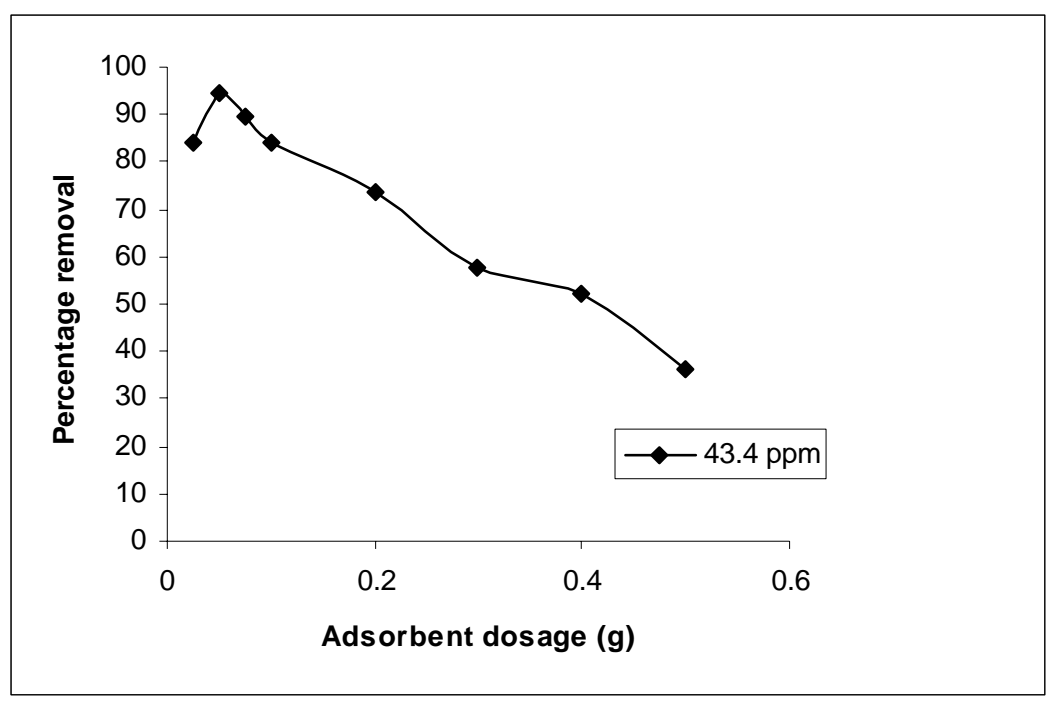

Figure 3. Effect of adsorbent dosage on percentage removal of $\mathrm{Ni}$ (II) from electroplating effluent

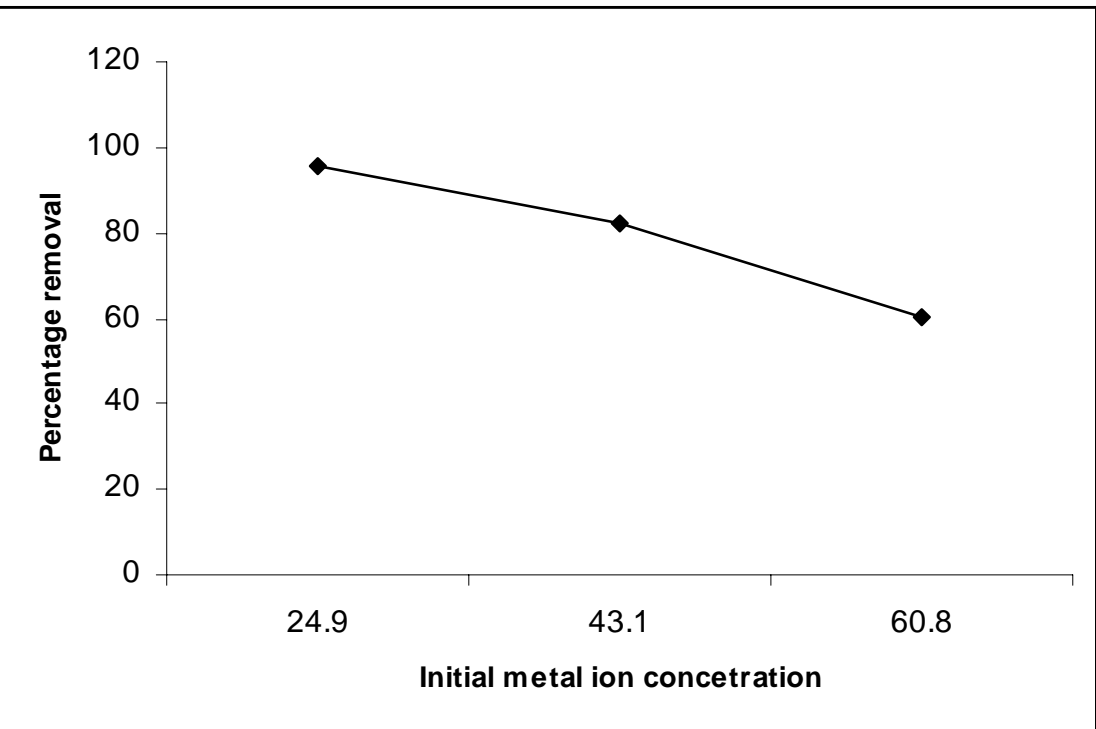

Figure 4. Effect of initial metal ion on percentage removal of $\mathrm{Ni}$ (II) from electroplating effluent 


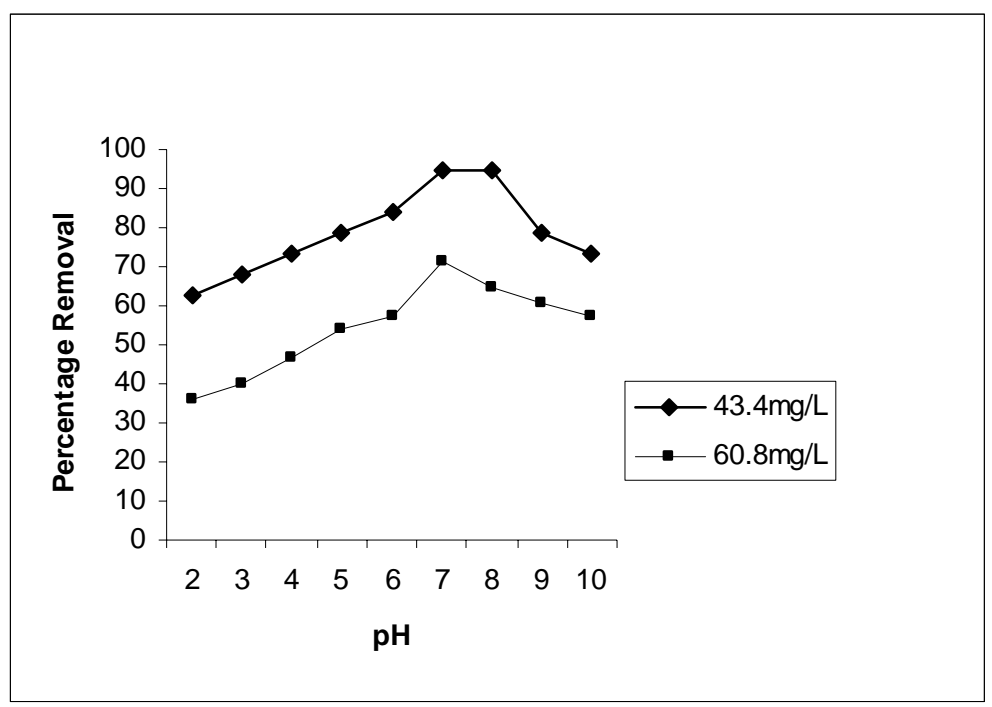

Figure 5. Effect of $\mathrm{pH}$ on percentage removal of $\mathrm{Ni}$ (II) from electroplating effluent

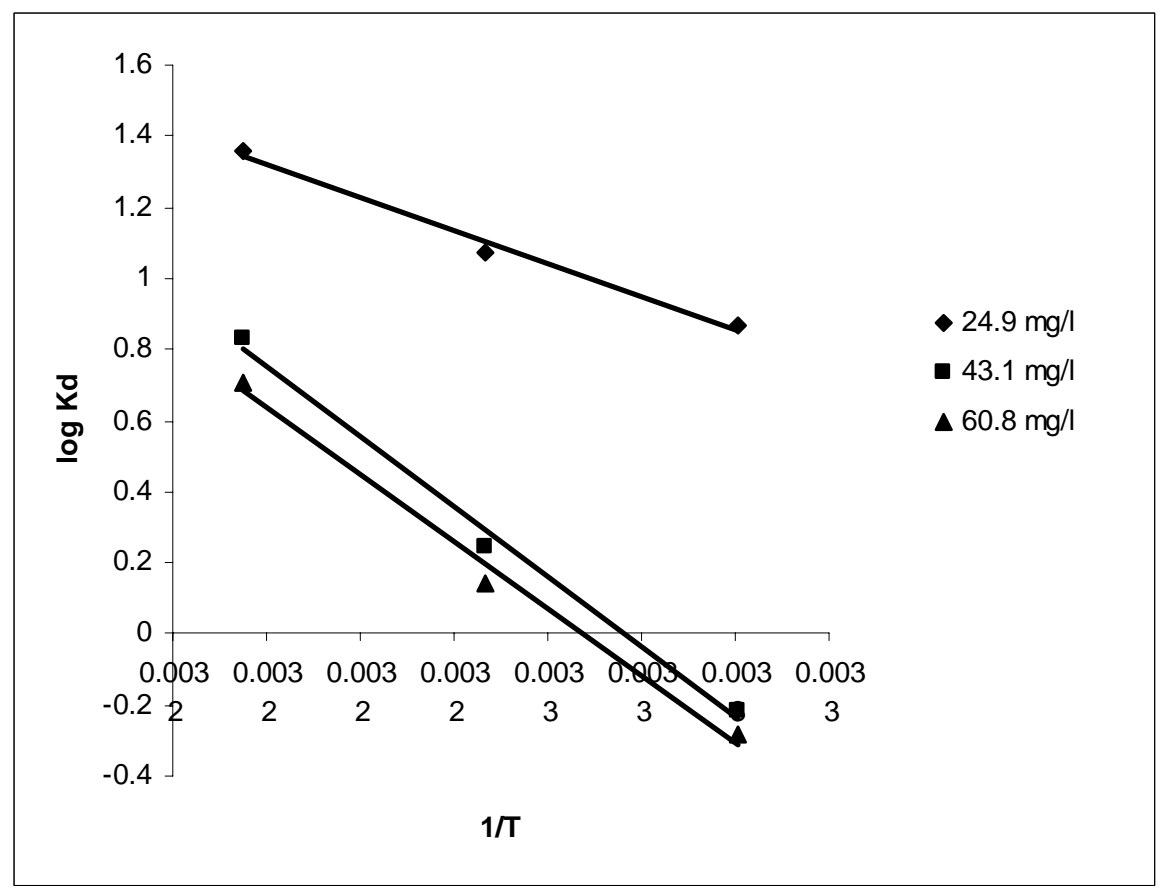

Figure 6. Effect of temperature on percentage removal for the removal of $\mathrm{Ni}$ (II) from electroplating effluent 


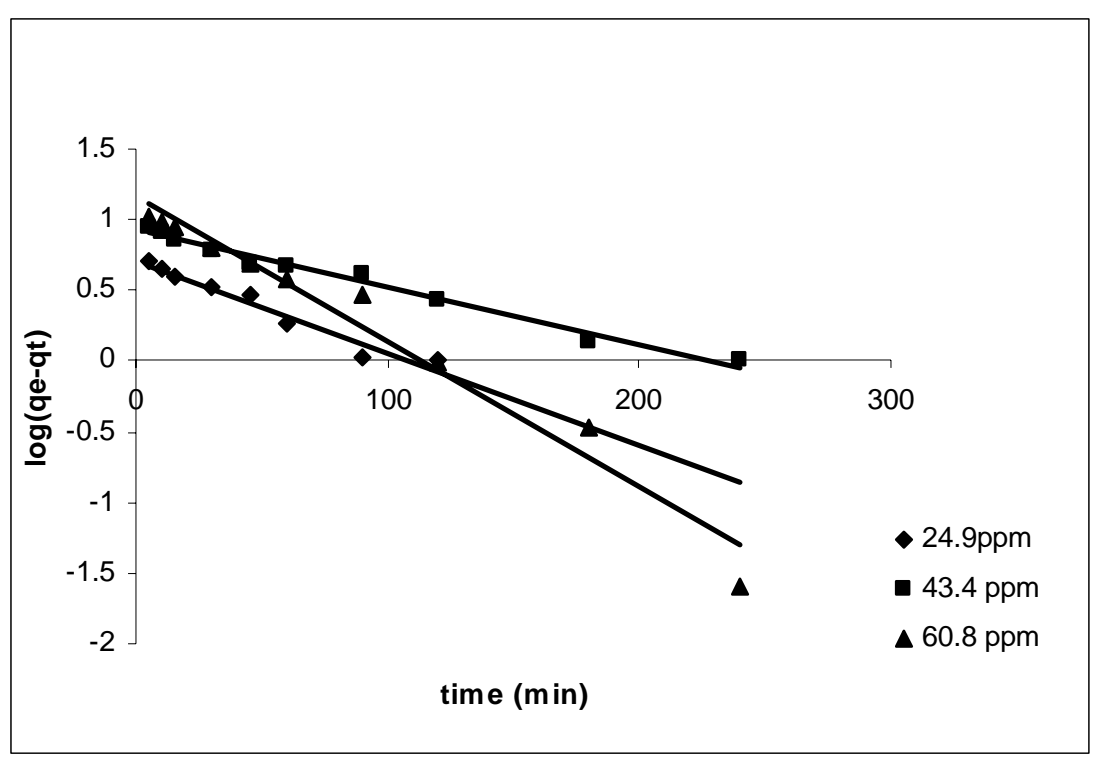

Figure 7. Pseudo - first - order for adsorption of Ni (II) from electroplating effluent

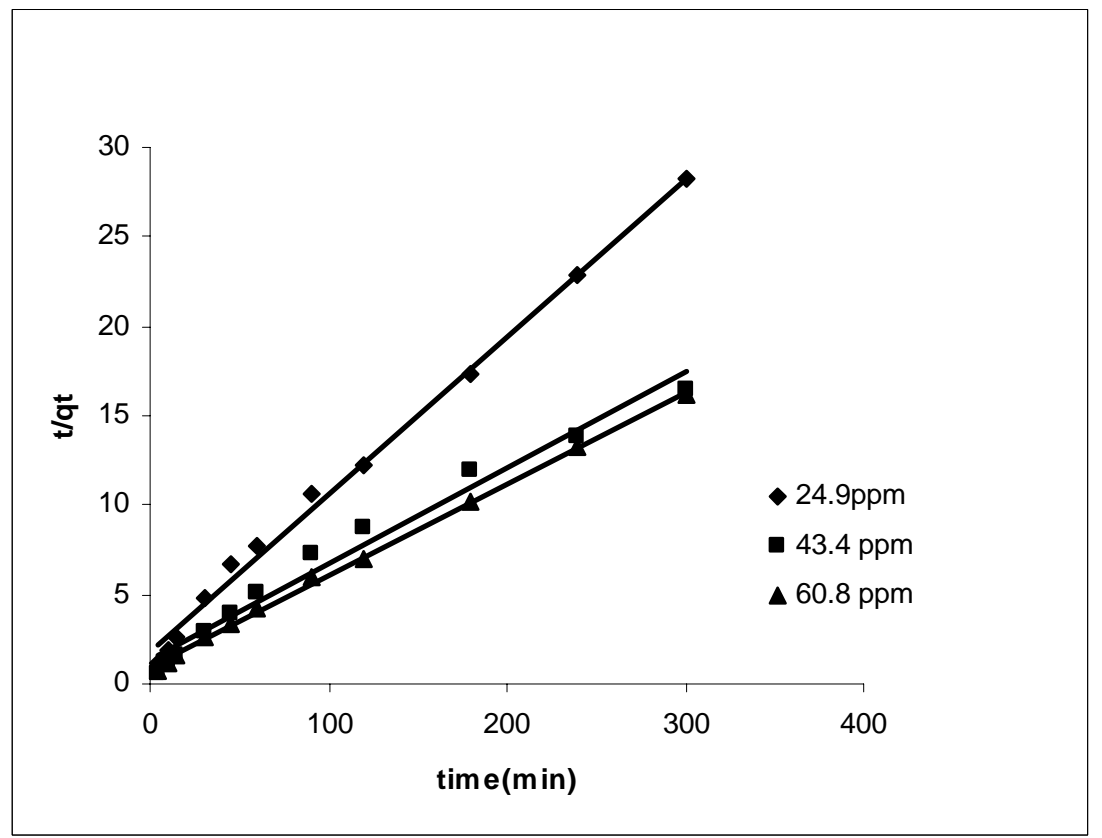

Figure 8. Pseudo - Second- order for adsorption of Ni (II) from electroplating effluent 


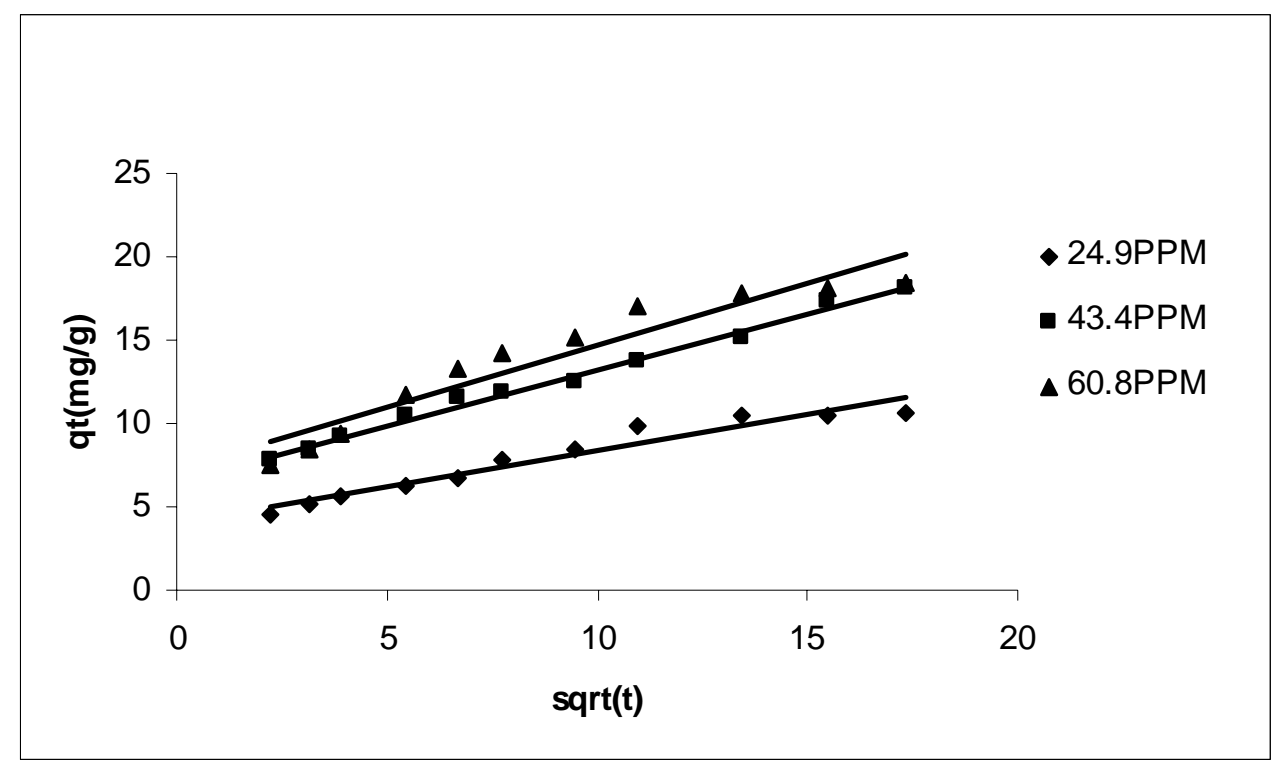

Figure 9. The Intra particle diffusion model for adsorption of $\mathrm{Ni}$ (II) from electroplating effluent

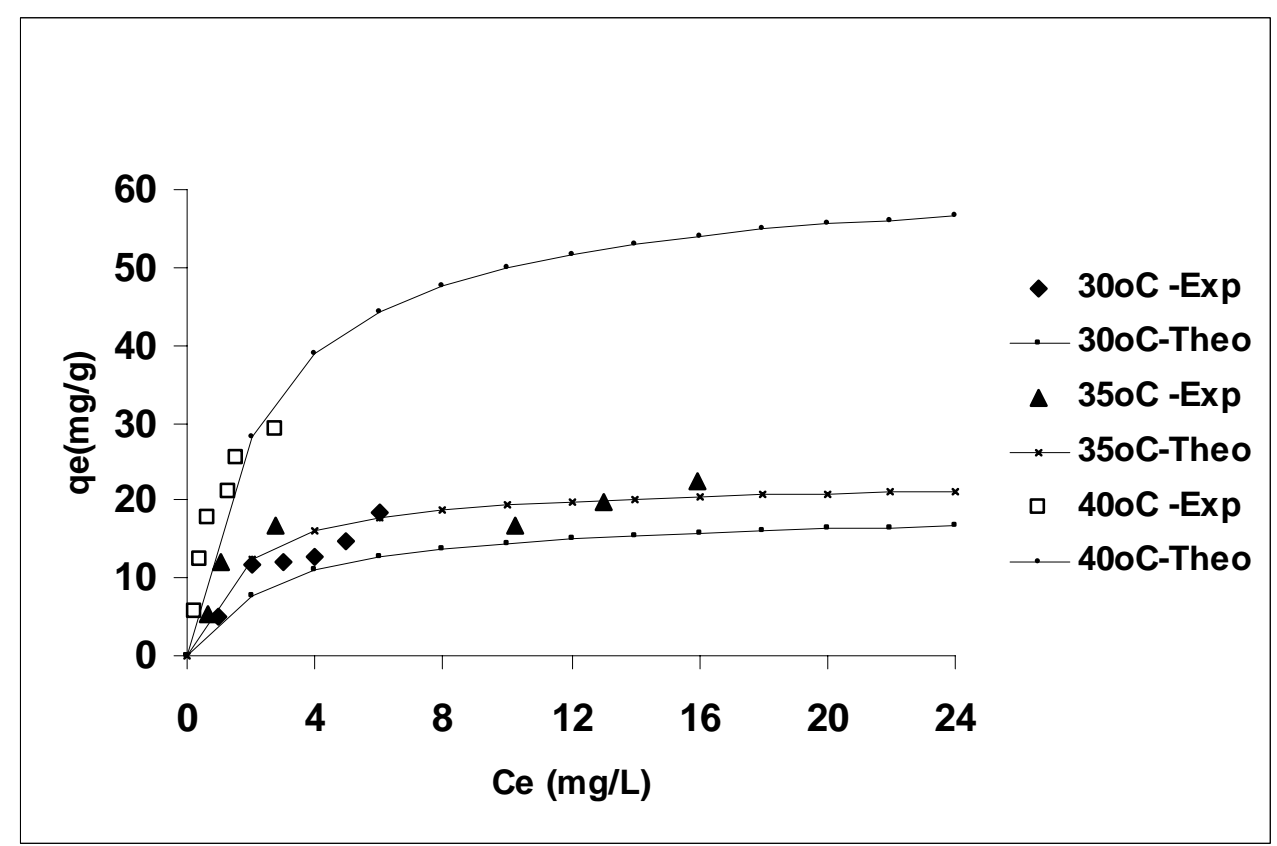

Figure 10. Langmuir plot for adsorption of $\mathrm{Ni}$ (II) from electroplating effluent 


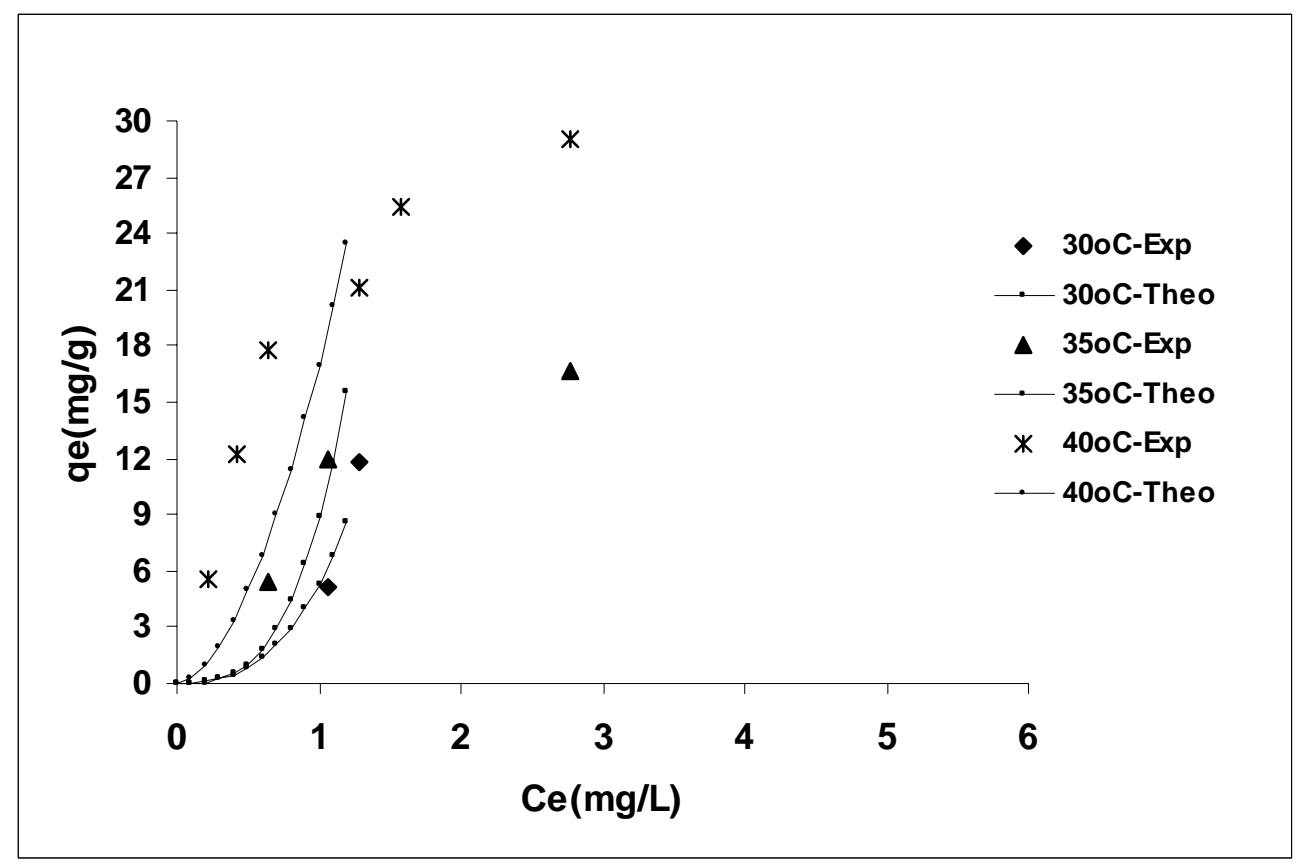

Figure 11. Freundlich isotherm for adsorption of Ni (II) from electroplating effluent

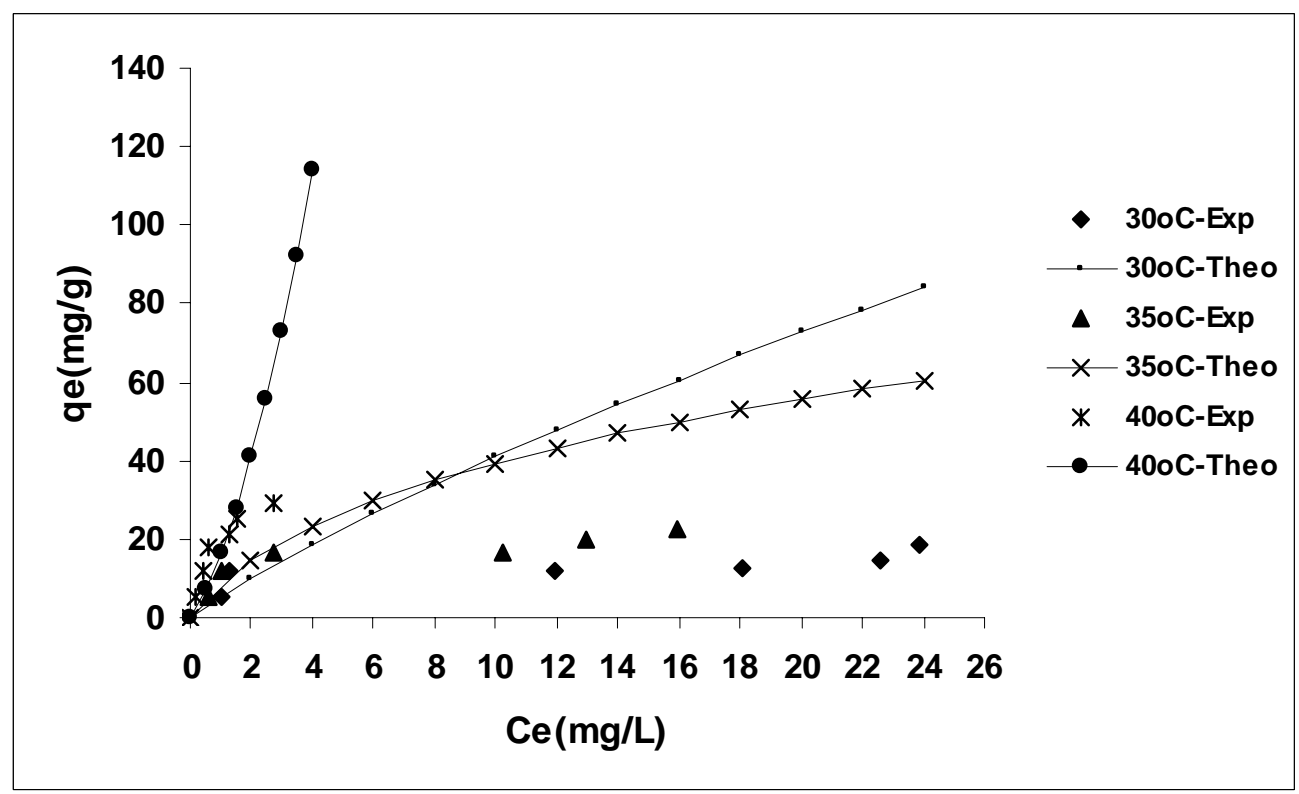

Figure 12. Redlich-Peterson isotherm for adsorption of Ni (II) from electroplating effluent 


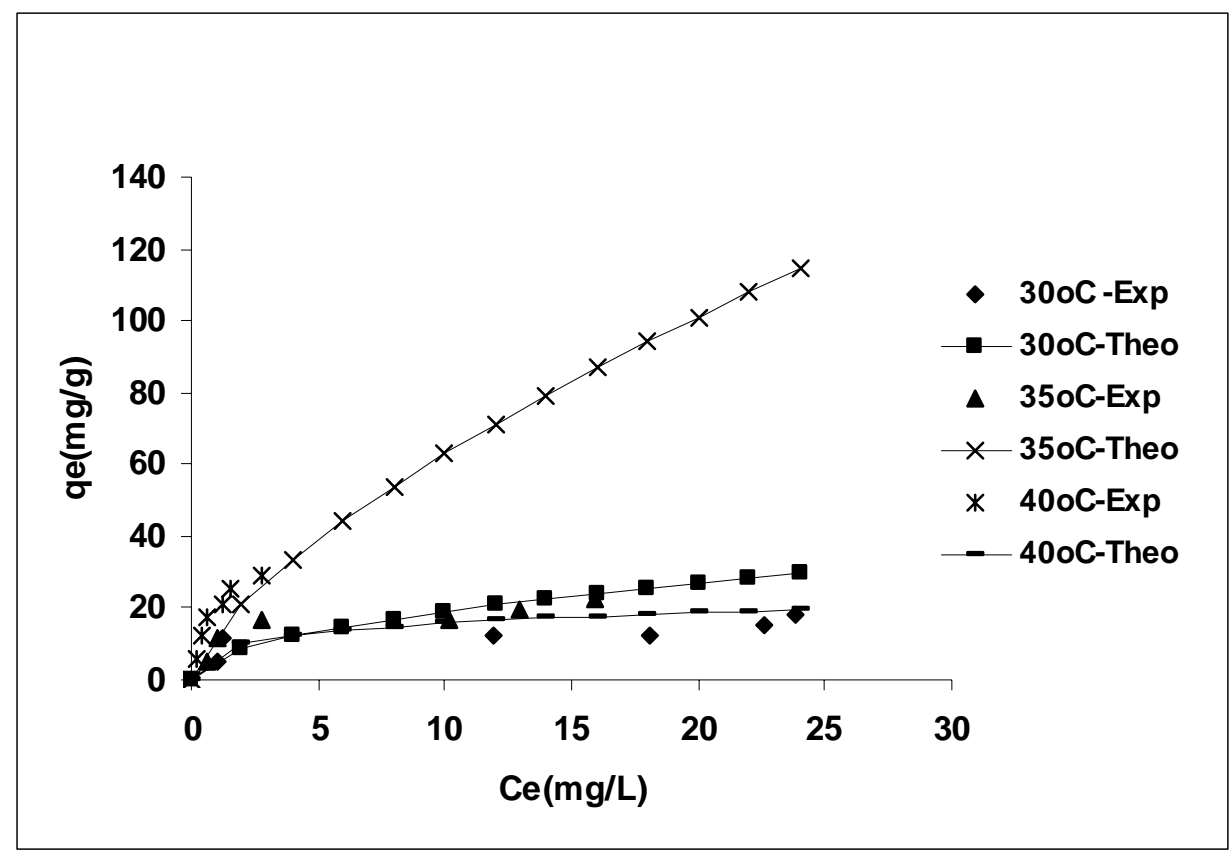

Figure 13. Sips isotherm for adsorption of Ni (II) from electroplating effluent 